\title{
Surgical Outcome of Total Knee Replacement
}

Dr. Md. Tofayel Hossain ${ }^{1 *}$, Dr. MD. Asaduzzaman ${ }^{2}$, Dr. Sanjoy Kumar Ghosh ${ }^{3}$, Dr. Abdul Kader ${ }^{4}$

\author{
${ }^{1}$ Associate Professor, Department of Orthopaedic Surgery, National Institute of Traumatology and Orthopedic \\ Rehabilitation (NITOR), Dhaka, Bangladesh \\ ${ }^{2}$ Assistant Register, Department of Orthopaedic Surgery, National Institute of Traumatology and Orthopedic \\ Rehabilitation (NITOR), Dhaka, Bangladesh \\ ${ }^{3}$ Medical Officer, Department of Orthopaedic Surgery, National Institute of Traumatology and Orthopedic Rehabilitation \\ (NITOR), Dhaka, Bangladesh \\ ${ }^{4}$ Assistant Professor, Department of Orthopaedic Surgery, Khulna Medical College, Khulna, Khulna, Bangladesh
}

DOI: $10.36347 /$ sjams.2020.v08i12.033

| Received: 05.12.2020 | Accepted: 16.12.2020 | Published: 29.12.2020

*Corresponding author: Dr. Md. Tofayel Hossain

\section{Abstract}

Original Research Article

Introduction: Total Knee Replacement (TKR) involves the surgically removing ailing cartilage and bone particles from the knee area, knee cap, shinbone, and thigh bone, and substitutes them with artificial joints made of metal alloys, high-grade plastics, or polymers. Although it is generally considered as an effective treatment for knee osteoarthritis and severe knee pain, complications after surgery can arise in various forms. Aim of the study: This study aimed to determine the surgical outcome of total knee replacement and the patient's experience after the surgery. Methodology: This observational study was conducted in the Department of Orthopaedic Surgery of National Institute of Traumatology and Orthopedic Rehabilitation (NITOR), Dhaka, Bangladesh during the period from March 2018 to April 2020. For this study, a total of 73 patients with severe knee pain was approached, compiled from a patient list of two different practitioners, to include a wide variety of demographic with varying characteristics, lifestyles and gender. Of them, 23 patients refused to participate in the study and share their information. The remaining 50 patients faced a basic interview describing their daily lifestyle, their pain severity, and any prior medical history they might have had. After this step, 23 patients were excluded from the list because their knee pain was manageable through medication and it was not necessary to perform TKR on them. Two more patients were excluded because they died of prior conditions before their surgery. Result: A Total of 35 patients most of the patients found male 14(40.0\%) and $21(60.0 \%)$ female patients with total knee replacement (Table-I). Also, 7(20.0\%) of them were aged under 50, $17(49.0$ $\%$ ) are aged between 51 to 70 , and the remaining 11(31.0\%) are aged 71 and above 10(28.57\%) of the sample patients had prior operations of orthopedical nature. From the range of collected data portrayed in the above bar chart, we can see that $60 \%$ of the sample size is female, and $40 \%$ are male. Most of the sample patients consist of older males and females, with the youngest being in their 40's. People between the age of 50-70 consist of the largest demographic between the sample patients. Photo I Left and Right Knee Before Sugary, Photo II The Surgery is going on Innovative Surgical Outcome of Total Knee Replacement photo before surgery and surgery is going on. Conclusion: During a total knee replacement, the end of the femur bone is removed and replaced with a metal shell. The end of the lower leg bone (tibia is also removed and replaced with a canneled plastic place with a metal stem. Knee conditions limit patient's activities of daily living due to pain and limited mobility. A benefit of knee replacement surgery is that is may be able to help patients resume a normal lifestyle.

Keywords: TKR, Knee, Surgery, Total Knee Replacement, Outcome, Observational, Arthroplasty.

Copyright $(\odot) 2020$ The Author(s): This is an open-access article distributed under the terms of the Creative Commons Attribution 4.0 International License (CC BY-NC 4.0) which permits unrestricted use, distribution, and reproduction in any medium for non-commercial use provided the original author and source are credited.

\section{INTRODUCTION}

Total knee replacement (total knee arthroplasty) is suggested for a patient who undergoes severe knee pain or stiffness, knee pain even during sitting or lying down, chronic inflammation or swelling, and knee deformities (a bowing in or out of the knee) among the other reasons as a basic treatment to function and relieve pain in patients. The surgery involves the replacement of both the medial and lateral femorotibial joints and the patellofemoral joint. Although total knee replacement is an effective treatment, postoperative complications may include blood clots, infection, and loosening or malalignment of the prosthetic component [1]. Despite improvements in implant designs and surgical precision, functional outcomes of mechanically aligned total knee arthroplasty (MA TKA) have plateaued. This suggests probable technical intrinsic 
limitations that few alternate more anatomical recently promoted surgical techniques are trying to solve [2]. Total knee arthroplasty (TKA) results in a high degree of patient satisfaction, as it provides patients with considerable medium- and long-term benefits in terms of quality of life, pain relief, and function. Nevertheless, the literature reports that up to $29 \%$ of patients are dissatisfied. This dissatisfaction is directly related to the patients' quality of life, which they deem insufficient [3]. In this case, patient satisfaction is greatly influenced by many outside factors, like their lifestyle pre-surgery, the environment, lack of post-operative exercise, obesity, and many others. Just as likely, some surgical factors can also play a part in their satisfaction after surgery, for example, phantom pain, a mishap while surgery, second-grade replacement parts, wearing of replacement parts, post-operative infection, blood clot, and others. This study is aimedto determine the surgical outcome of total knee replacement and the patient's experience after the surgery

\section{OBJECTIVES}

\section{a. General objective}

- To determine the outcome of a surgical knee replacement.

\section{b. Specific Objectives}

- To determine the percentage of people who face difficulties after TKR

- To determine the factors which play a role in unsatisfactory lifestyle in post-operative patients

\section{Methodology \& Materials}

This was an observational study and was conducted in the National Institute of Traumatology and Orthopedic Rehabilitation, Dhaka, Bangladesh during the period from March 2018 to April 2020. This study was conducted through a detailed interview of 50 patients, of which, 35 patients went through a separate second stage interview one year after their knee replacement surgery. So the sample size for this study will be 35 only. A large number of patients are admitted daily to this institute, mostly with bone fractures and bone-related issues. This particular study was concluded by focusing only on patients with severe knee pain and stiffness.

\section{Inclusion Criteria}

- Patients of both gender
- $\quad$ Patients with severe knee pain

\section{Exclusion Criteria}

- Patients who would not give consent.

- Unstable patients with severe prior complications who died before the surgery

For this study, a total of 73 patients with severe knee pain was approached, compiled from a patient list of two different practitioners, to include a wide variety of demographic with varying characteristics, lifestyles and gender. Of them, 23 patients refused to participate in the study and share their information. The remaining 50 patients faced a basic interview describing their daily lifestyle, their pain severity, and any prior medical history they might have had. After this step, 23 patients were excluded from the list because their knee pain was manageable through medication and it was not necessary to perform TKR on them. Two more patients were excluded because they died of prior conditions before their surgery. The remaining 35 patients make up the core of this study and they went through a detailed second interview 1 year after their surgery to see whether or not they face any complications or changes in their daily lifestyle. The data analysis of this case study was done by Microsoft excel.

\section{RESUlT}

A Total of 35 patients most of the patients found male $14(40.0 \%)$ and $21(60.0 \%)$ female patients with total knee replacement (Table-1). Also, 7(20.0\%) of them were aged under 50, 17(49.0\%) are aged between 51 to 70 , and the remaining $11(31.0 \%)$ are aged 71 and above $10(28.57 \%)$ of the sample patients had prior operations of orthopedical nature. From the range of collected data portrayed in the above bar chart, we can see that $60 \%$ of the sample size is female, and $40 \%$ are male. Most of the sample patients consist of older males and females, with the youngest being in their 40's. People between the age of 50-70 consist of the largest demographic between the sample patients.

Table-1: Sex Distribution of Surgical Outcome of Total Knee Replacement $(\mathbf{n}=35)$

\begin{tabular}{|l|l|l|}
\hline Sex & n & \% \\
\hline Male & 14 & 40.0 \\
\hline Female & 21 & 60.0 \\
\hline
\end{tabular}




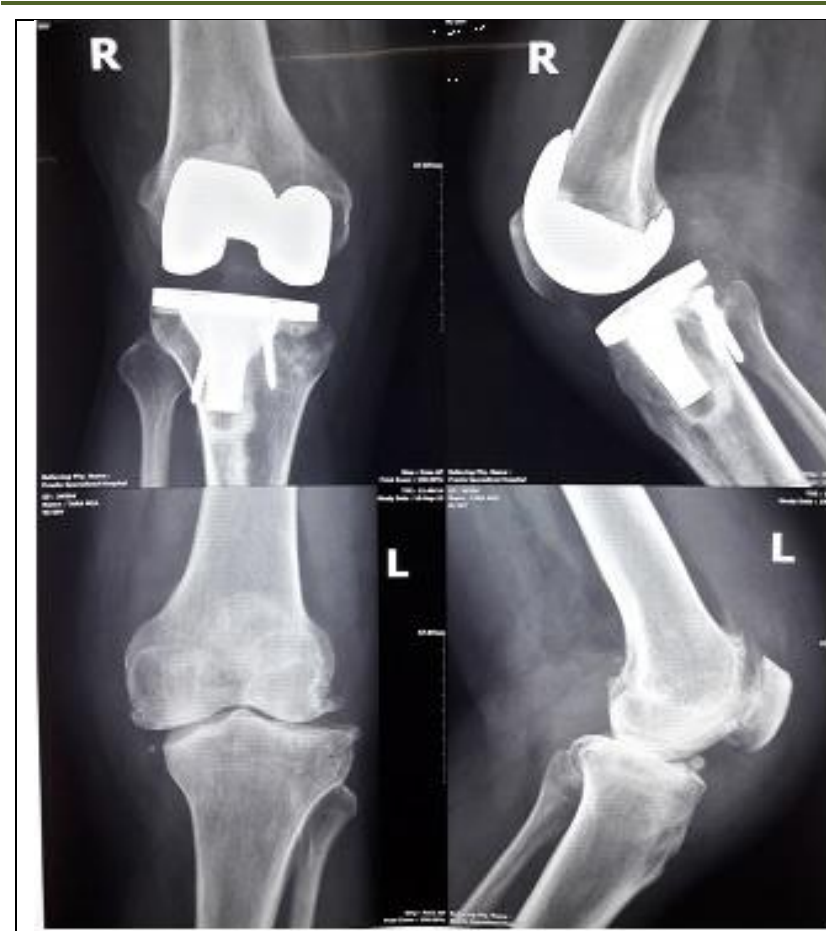

Photo I: Pre Operative X-ray

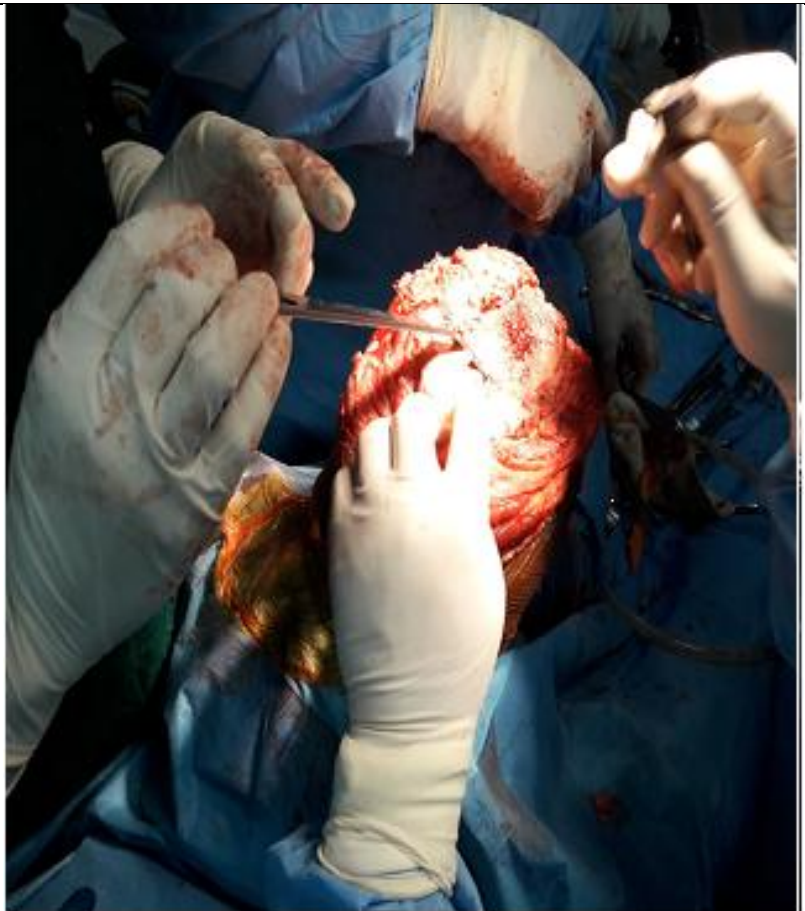

Photo II: Post operative X-Ray

Innovative Surgical Outcome of Total Knee Replacement photo before surgery and surgery is going on.

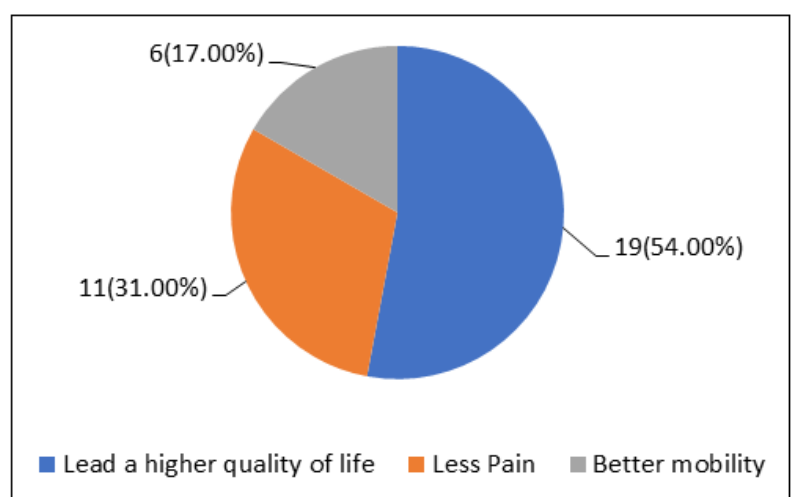

Fig-1: Surgical Outcome of Total Knee Replacement

\section{DISCUSSION}

From the collected data and the created analysis of them, we can see that the ratio of female patients to male patients is higher by $20 \%$. One possible reason for this outcome can be the calcium deficiency present in most of the female population. Another trend that can be noticed here is the age group, as patients under the age of $50 \%$ have a very low chance of needing a knee replacement, and people between the age group of 51 to 70 have a high likelihood of getting knee replacement surgery done. After the age of 70, even though the patients might need knee replacement surgery, their physical limitations don't always allow that. And at that age, they also lose motivation for doing any kind of major surgery. But after the surgery was done, patients that had been properly taken care of for a certain time responded positively when asked how their lifestyle was one year after the surgery. 54\% regarded their lifestyle as Excellent, and $17 \%$ regarded it as satisfactory. $31 \%$ responded that their lifestyle postsurgery was not satisfactory, but in all of these cases, outside factors remain and influence the outcome. On each follow-up examination, every patient received an original questionnaire with 24 questions concerning the course of their post-operative period (between the discharge from the hospital and the planned follow-up). The patients assessed the degree of satisfaction with surgery outcomes on a scale ranging from "fully satisfied" to "dissatisfied" and expressed their overall satisfaction in percent [5]. It can be surmised that follow-up treatments, both surgical and non-surgical in nature can affect a patient's lifestyle and satisfaction regarding surgery long after the surgery is over. It is relevant to emphasize that subjective factors, such as expectation or satisfaction, do not depend on the therapeutic procedure only. Recent reports have shown that in $10 \%$ to $30 \%$ of the patients, the TKR outcome has not met their expectations. ${ }^{[5]}$ In most cases, patients facing any kinds of problems after TKR are likely to believe that any discomfort they are feeling might be because they did something wrong, and not because the surgery went bad. Many believe, despite being in the same amount of pain after the surgery as they were in before, that patients tend to think that they are "bound to get better" after a certain period, and therefore regard their outcome as good [4]. While running a separate research study to see the rate of improvements between patients with moderate to severe knee pain, a greater scale of improvement could be seen in the patients undergoing surgery, compared to patients relying on only non-surgical methods the dissatisfaction patients showed is directly related to their quality of life, which they deem insufficient. This can depend on many 
Tofayel Hossain et al; Sch J App Med Sci, Dec, 2020; 8(12): 2855-2859

physical, behavioral, social, and psychological factors that are not taken into account by functional outcome scores [6]. It has been decided that mainly three parameters affect patient satisfaction the most, functional outcomes, level of residual pain, and any prior expectations the patient might have had preoperation [6]. A detailed analysis of the patient-reported functions and pain management has shown that after TKR, the pain outcomes have begun to worsen gradually over time. This time trend may be influenced by patient activity after TKR, their job, and lifestyle, and other environmental factors [7]. It has also been observed that patients' psychological state has a valid effect on patients' satisfaction toward the surgery, as patients with depressions voted the surgery unsatisfactory even though they received the exact surgery as the other patients [8]. Although small, there was a risk of having knee infection from the surgery, which also influenced the decision making of the patients. Nevertheless, patients concluded their TKR as successful, despite facing continuous pain, as they made varying reasons and rationalizations for the remaining pain. ${ }^{[4]}$ The study, cross-referenced with another implies that the age or obesity of the patient does not negatively impactthe patient-related outcomes [9]. It is apparent that TKR can only elevate the pain and not erase it, but the biggest factor in deciding the satisfaction of a patient was the existing pain after surgery. As this study was conducted over a short pool of samples and a short time frame, further analysis is needed to determine whether the outcome improves or deteriorates over a longer period. It has been observed that patients who tend to move a lot, need to climb stairs, and are unable to use elevators, patients in an occupation that require standing or sitting in the same place for a long time, are more likely to feel unsatisfied with the surgery, as these activities are very distressing and still play a part in the patients daily life [10]. While cross-referencing research by SKAR which was done via a questionnaire, it has been concluded that the amount of time postsurgery directly influences the satisfaction of a patient, as they are more likely to have worn out the prosthetic knee parts overuse of a long time [11]. Crossreferencing another research concludes that sociodemographic factors, pre-operative occupation, joint functions, and surgical and rehabilitation-related factors are associated with post-operative work status [12]. Another possible criterion for dissatisfaction, especially for this country, is not being able to pray, which requires kneeling and sitting for a longer period and puts more pressure on the knee joints than necessary [13, 14]. It has also been observed that patients over the age of 70 are the most satisfied with their surgery, as they often do not need to participate in any strenuous and tiresome work, despite the high mortality rate [3]. Overall evaluation of the current data leads us to believe that women are more likely to need TKR than men, after a successful TKR/TKA, patients are mostly satisfied with the surgery, excluding a few cases. The patient's satisfaction or dissatisfaction is generally influenced by their pre-operation and postoperation lifestyle, occupation, and expectations. Patients over the age of 70 are generally more satisfied with their operation. But having a small data pool, we can not yet reach any further analysis as these statements might change after moire time passes, and there is a need to continue the research via more checkups and interviews with the current sample size intermittently over a long period, preferably a yearly review going up to 6-7 years.

\section{Limitations of The STUdy}

Our study wasn't blinded so patient bias was present along with observer bias in subjective recording and the

\section{CONCLUSION}

During a total knee replacement, the end of the femur bone is removed and replaced with a metal shell. The end of the lower leg bone (tibia is also removed and replaced with a canneled plastic place with a metal stem. Knee conditions limit patient's activities of daily living due to pain and limited mobility. A benefit of knee replacement surgery is that is may be able to help patients resume a normal lifestyle. In our study, we found some superiority of oral TXA with fluocinolonebased triple combination cream over.

Funding: No funding sources.

Conflict of interest: None declared.

Ethical approval: The study was approved by the Institutional Ethics Committee.

\section{REFERENCES}

1. Scott AM. Total Knee Replacement and Imaging. Radiol Technol. 2015 Sep-Oct;87(1):65-86.

2. Rivière $\mathrm{C}$, Iranpour $\mathrm{F}$, Auvinet $\mathrm{E}$, Howell $\mathrm{S}$, Vendittoli PA, Cobb J, Parratte S. Alignment options for total knee arthroplasty: a systematic review. Orthopaedics \& Traumatology: Surgery \& Research. 2017 Nov 1;103(7):1047-56.

3. Canovas F, Dagneaux L. Quality of life after total knee arthroplasty. Orthopaedics \& Traumatology: Surgery \& Research. 2018 Feb 1;104(1):S41-6.

4. Woolhead GM, Donovan JL, Dieppe PA. Outcomes of total knee replacement: a qualitative study. Rheumatology. 2005 Aug 1;44(8):1032-7.

5. Lošt’ák J, Gallo J, Zapletalová J. Spokojenost s náhradoukolena: analýzapředoperačních a perioperačníchparametrů u 826 pacientů [Patient Satisfaction after Total Knee Arthroplasty. Analysis of Pre-Operative and Peri-Operative Parameters Influencing Results in 826 Patients]. Acta Chir Orthop Traumatol Cech. 2016; 83(2):94-101. 
6. Canovas F, Dagneaux L. Quality of life after total knee arthroplasty. Orthopaedics \& Traumatology: Surgery \& Research. 2018 Feb 1;104(1):S41-6.

7. Singh JA, Lewallen DG. Are outcomes after total knee arthroplasty worsening over time? A timetrends study of activity limitation and pain outcomes. BMC musculoskeletal disorders. 2014 Dec 1;15(1):440.

8. Ellis HB, Howard KJ, Khaleel MA, Bucholz R. Effect of psychopathology on patient-perceived outcomes of total knee arthroplasty within an indigent population. JBJS. 2012 Jun 20;94(12):e84.

9. Hawker G, Wright J, Coyte P, Paul J, Dittus R, Croxford R, Katz B, Bombardier C, Heck D, Freund D. Health-related quality of life after knee replacement. Results of the knee replacement patient outcomes research team study. Jbjs. 1998 Feb 1;80(2):163-73.

10. Nakahara H, Okazaki K, Mizu-uchi H, Hamai S, Tashiro Y, Matsuda S, Iwamoto Y. Correlations between patient satisfaction and ability to perform daily activities after total knee arthroplasty: why aren't patients satisfied?. Journal of Orthopaedic Science. 2015 Jan 1;20(1):87-92.

11. Robertsson O, Dunbar M, Pehrsson T, Knutson K, Lidgren L. Patient satisfaction after knee arthroplasty: a report on 27,372 knees operated on between 1981 and 1995 in Sweden. Acta Orthopaedica Scandinavica. 2000 Jan 1;71(3):2627.

12. Leichtenberg CS, Tilbury C, Kuijer PP, Verdegaal $\mathrm{SH}$, Wolterbeek R, Nelissen RG, Frings-Dresen $\mathrm{MH}$, Vliet Vlieland TP. Determinants of return to work 12 months after total hip and knee arthroplasty. The Annals of The Royal College of Surgeons of England. $2016 \mathrm{Jul} ; 98(6): 387-95$.

13. Niki Y, Takeda Y, Harato K, Suda Y. Factors affecting the achievement of Japanese-style deep knee flexion after total knee arthroplasty using posterior-stabilized prosthesis with high-flex knee design. Journal of Orthopaedic Science. 2015 Nov 1;20(6):1012-8.

14. Kim DK, Seo MC, Song SJ, Kim KI. Are Korean patients different from other ethnic groups in total knee arthroplasty?. Knee surgery \& related research. 2015 Dec;27(4):199-206. 